\title{
THE FUTURE SETTING OF THE DESIGN STUDIO
}

\section{Burcu Senyapili \& Ahmet Fatih Karakaya}

\begin{abstract}
This study explores the impact of virtual classrooms as an emerging classroom typology in comparison to the physical classrooms in the design process. Two case studies were held in order to infer design students' classroom preferences in the project lifecycle. The findings put forth figures that compare two forms of design communication in the two classroom types in terms of their contribution to design development. Although the students acknowledged many advantages of web-based communication in the virtual classroom, they indicated that they are unwilling to let go off face-to-face encounters with the instructors and fellow students in the physical classroom. It is asserted that the future design studio will be an integrated learning environment where both physical and virtual encounters will be presented to the student. Utilizing the positive aspects of both communication techniques, a hybrid setting for the design studio is introduced, comprising the physical classroom as well as the virtual one. The proposed use for the hybrid setting is grouped under 3 phases according to the stage of the design process; as the initial, development and final phases. Within this framework, it is inferred that the design studio of the future will be an integrated form of space, where the physical meets the virtual.
\end{abstract}

Keywords: Classroom, Design Studio, Hybrid Course, Learning Environment.

\section{INTRODUCTION}

Design education is generally carried out in design studios, where design students communicate on their projects with their instructors and fellow students. In the design studio students express themselves, introduce and discuss ideas, generate and evaluate alternatives, and make decisions based on given projects. In the traditional design studio setting, student-instructor communication is held faceto-face, through physical encounters. The possibility of face-to-face interaction is a key advantage of the place-based offering. It is through this interaction that the students improve skills as presentation and debate (Parker and Rossner-Merrill, 1998). Hundhausen et.al. indicate that the key features of the studio-based education are construction and presentation of representations (Narayanan and Crosby, 2008).

With recent developments in technology however, Internet-based platforms emerged as an alternative to the face-to-face design communication and to the physical encounters in the classroom. Web-based communication seems to eliminate the prerequisites related to the physical classroom setting, such as having to be in the classroom at a specific time, by enabling the virtual classroom alternative (Norman, 2001; Reffat, 2002; Kalay, 2004; Clark \& Maher, 2005). The virtual classroom also allows for having feedback in written form for further and repeated reference. Students no longer have to come to the design studio with drawings and scaled models, and wait for the specific time interval to meet with the design instructor to get face-to-face oral critiques. They can now load their drawings or $3 \mathrm{~d}$ files on a website or attach them to e-mails, and get written critiques on their designs within a pre-determined time interval.

As the virtual opportunities emerged, soon it became inevitable to discuss the future of design education and the implications of the virtual opportunities on the design pedagogy (Clayton, 2000; Andia, 2002; Oxman, 2007; Akkoyunlu \& Soylu, 2008). Based on the advantages of the virtual classrooms and given the strong background of this generation of students in using and being familiar with computers, with a rushed presumption one might assert that majority of the design students would prefer to use web-based design communication. Extending the presumption, it may be expected that as the students use Internet-based communication, they will attend to the design stu- 
dio less, deserting the physical classroom.

Within this framework, two consecutive studies with two different student groups were held involving both physical and virtual classroom settings. The aim was to infer design students' classroom preferences in the project lifecycle. In order to determine their preferences a special focus was cast upon the communication techniques used in both classroom settings. In the physical design studio communication is held face-to-face, wheras in the virtual one the communication is held through webbased techniques.

Current generation of design students comprises members of an age group who were introduced with computers at an early age. Even though they may not have started using computers at early ages, they regard and accept computers as part of daily life. It is worth investigating whether this situation leads them to favor computers for design communication. Moreover, it is intriguing whether students become more self-focused using computers for design communication rather than getting socialized in the design studio.

\section{HYBRID LEARNING ENVIRONMENTS}

In higher education, in fields other than design, with the incorporation of new educational techniques, hybrid courses have been developed (Latchman, 1998; Dennis etal., 2002; Koohang \& Durante, 2003; El-Gayar \& Dennis, 2005; Sigle etal., 2005; Nguyen \& Bodi, 2007).

Hybrid courses are courses in which a significant portion of the learning activities takes place online. Hybrid courses reduce, but do not totally eliminate, the time spent in the classroom. According to Garnham and Kaleta (2002), the goal of hybrid courses is to join the best features of in-class teaching with the best features of online learning to promote active independent learning and reduce class seat time. Accessibility to the course content, effectiveness of large lecture instruction, and level of connectivity between students and instructor are advantages of hybrid courses over the traditional face-to-face physical classroom encounters (Poltrock \& Engelbeck, 1999; Cheng \& Kvan, 2000; Johnson, 2002). In the fields where hybrid courses are practiced, studies demonstrate that few students have difficulty using the technology; and the instructor spends more time on individual communication compared to a regular class (Hensley, 2005).
In an earlier study, Benbunan-Fich and Hiltz (2003) found that there were no significant differences in the perceived learning by students between three modes of courses; traditional, mixed and totally online. They suggested that such studies need to be carried out in other fields than theirs. This study introduces a mixed (face-to-face and online) setting for the design studio to find out the students' assesments of the setting. The structure of the online activities is different in design considering that in many other fields the content travels one-way from the instructor to the student, whereas in the design studio, the content travels back and forth in revised versions (Levine \& Wake, 2000). Therefore, the findings of the use of online activities in the design studio may differ from those in other fields. In this study the impacts of face-to-face communication through physical encounters and web-based communication through virtual encounters are examined. Al-Qawasmi (2006) discussed the transformations in design education after the emergence of the virtual and paperless design studios under several titles including 'peer learning', inferring that the basic assumptions are changed in the traditional deisgn studio. This study is an attempt to explore the direction which these changes are pointing to.

\section{CASE STUDIES}

The case studies focus on the preferences of the design students about physical and virtual encounters. We worked with the 3rd and 4th year students of the interior architecture curriculum at Bilkent University Faculty of Art, Design and Architecture, to see their tendencies in preferring the physical and the virtual classroom.

The students enrolled in an elective design course in two different semesters have participated in the studies. The students were asked to develop design projects through physical and virtual encounters. Physical encounters comprised the face-to-face meetings and discussions in a designated design studio. Virtual encounters involved web-based communications using specific communication platforms. At the end of each semester the students were asked to fill in questionnaire forms assesing their satisfaction and inquiring about the strong and weak aspects of both encounters.

\section{First Study}

13 students participated in the first study, who were 


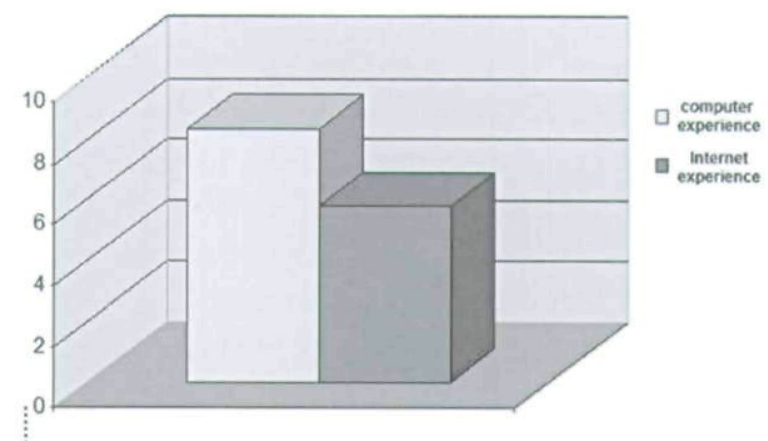

Students' background in terms of years in using computer and Internet

enrolled in an elective course. Students formed groups of 3-4 to work on a given project. Total duration of the project was 6 weeks. A 3-hour course was held each week. There was one pre-jury (comprising 3 design instructors) during the project period. Students had the chance to have physical class hours each week (except for the jury week) and for the rest of the week they had the opportunity to communicate virtually through a server space specially allocated for the course (Senyapili \& Karakaya, 2005).

\section{Second Study}

In the second study, 16 design students were enrolled in the same elective design course. Design students constituted 4 groups, each group composing of 4 students. This time, the design project duration was 8 weeks, with one 3 -hour course each week, except for one week dedicated to the prejury. During the semester the students were required to have physical encounters as well as virtual ones, which were held through a special platform 'Virtual Campus' developed by Bilkent University (Senyapili \& Karakaya, 2006).

\section{KEY FINDINGS}

The findings are grouped in three main categories composing of:

- students' background in using computers,

- students' assesment of face-to-face and web-

based communications separately,

- students' evaluation of the both communications comparatively.

\section{Students' Background in Using Computers}

In a previous study, Koohang and Durante (2003) found that experience with the Internet was a significant factor in learners' perception toward web-

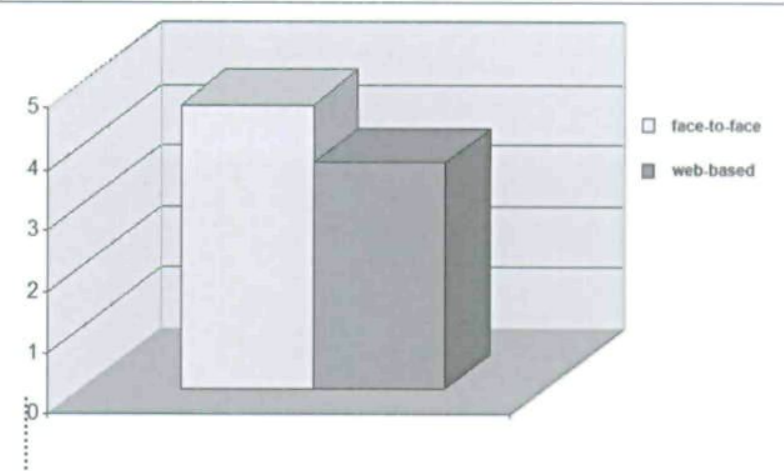

Favored communication technique preferences using a $7-5$ scale

based learning. In this study, initially students' experience in computer use was determined. All students had previous computer experience. Second group of students were more experienced with computers. In the first study, the student with the least computer experience had 3 years of experince (mean= $7,46)$, whereas in the second study the least was 6 years $($ mean $=9,18)$. Students indicated that they use computer for mostly writing, drawing, and connecting to the Internet. Especially regarding the Internet use, the mean of years of using the Internet for first group of students was 5,41, and 6,18 for the second group of students (Figure 1). Both student groups were familiar with computers, used to navigating in the Internet as well. Therefore, students were not expected to have difficulties in terms of handling virtual tools.

\section{Assesment of Face-to-Face and Web-based Communication Separately}

In the questionnaires, students were asked which type of communication they found useful the most. Major part of the students said that both techniques were useful, while a few favored face-to-face communication alone. Students were asked to evaluate both types of communications on a 1 to 5 scale, 5 being 'very helpful', and 1 corresponding to 'not helpful at all'. In both studies, face-to-face communication were favored more than web-based communication (for the first study the mean for face-toface was 4,69 and and for web-based 3,53) (for the second study the mean for face-to-face 4,62 and for web-based was 3,87) (Figure 2).

Both communication techniques were tested in terms of a given set of criteria, each item being evaluated on a 5-point scale, the criteria being:

- Understanding the critiques

- Preparation load for presentation

- Quality of presentation

- Changes on the design after the critique 


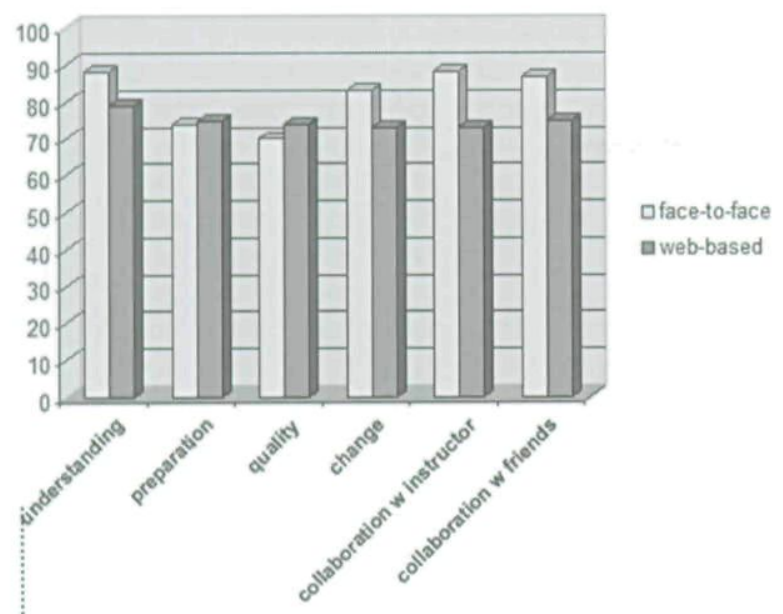

Figure 3. Assesment of face-to-face and web-based communication in both studies

- Collaboration with the instructor

- Collaboration with the friends

For face-to-face communication the highest mean (Mirst sudy $=4,76, M_{\text {second study }}=4,37$ ) was received in terms of understanding the critiques in both studies. This result indicates that understanding the critiques via face-to-face communication was evaluated as being easy by the students. For face-to-face communication, the least mean was equally received for both preparation load for presentaion and quality of presentation (M $M_{\text {firs study }}=3,76$ ). In the second study, the least mean was received for quality of presentation $(M=3,28)$ and similar to the first study, preparation load for presentation received the second lowest mean $(M=3,76)$. These results showed that for face-to-face critiques students thought that the preparation load for presentations was dense and they were not satisfied with the quality of the presentations.

For web-based communication, in the first study the highest mean was received for understanding the critiques $(M=4,30)$, in the second study for collaboration with friends $(M=4,03)$. The least means for web-based communication was received for changes on the design after the ciritique in the first study $(M=3,30)$, and for presentation quality in the second study $(M=3,40)$ (Figure 3)(Table 1).

The most preferrable aspect of face-to-face communication in both studies turned out to be understanding the critiques. This shows that although the face-to-face critiques are not written and do not offer the chance of repeated reference, students still value the advantages of face-to-face communication, such as;

- facial expressions,

- instant response,

- complimentary figures of speech,

- gestures.

Interestingly, in the second study, web-based communication received the highest mean for understanding the critiques, with a slight difference in the mean. This provides grounds to argue that students acknowledge the positive assets of the web-based communication as well, which helped them in comprehending the critiques on their designs, such as;

- clear and concise critique text,

- chance of repeated references,

- chance of discussing with others over the critique text.

It seems to be no coincidence that both face-toface and web-based communication have received least means for quality of presentation since students tended to blame presentation's inadequencies for the shortcomings of their design.

\section{Comparative Assesment of Face-to-Face and} Web-based Communication

A set of 5 point scale was used to obtain an over-

\begin{tabular}{|c|c|c|c|c|c|c|}
\cline { 2 - 7 } \multicolumn{1}{c|}{} & understanding & preparation & quality & change & coll w/inst. & coll w/friends \\
\hline f-t-f 1 & 4,76 & 3,76 & 3,76 & 4,26 & 4,56 & 4,71 \\
\hline f-t-f 2 & 4,37 & 3,76 & 3,28 & 4,37 & 4,37 & 4,08 \\
\hline w b 1 & 4,30 & 3,55 & 4,00 & 3,30 & 3,70 & 3,45 \\
\hline w b 2 & 3,52 & 3,09 & 3,40 & 3,91 & 3,61 & 4,03 \\
\hline & & & & & &
\end{tabular}

Assesment of communication types (face-to-face 4-t-f and web-based ' $w b$ ') in the first and second studies 


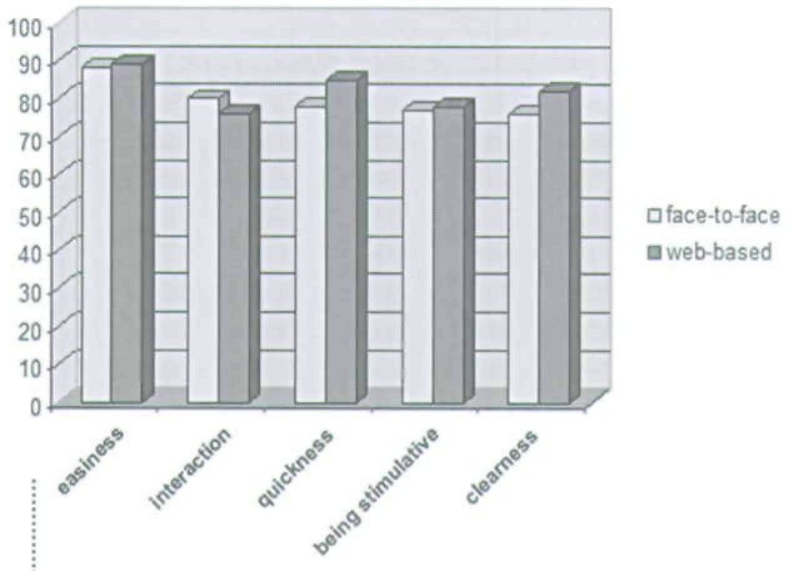

Figure 4. Comparative assessment of face-to-face and web-based communication in the design studio

all evaluation of both types of communication, in terms of easiness, interaction, quickness, stimulation capacity, and clearness.

In the first study, face-to-face communication received highest mean for easiness $(M=4,46)$ and least $(M=3,84)$ for being stimulative. Web-based critiques, similarly, received highest mean for easiness $(M=4,53)$ and least $(M=3,69)$ for being stimulative. This result is very interesting as it shows that there is a comparatively students indicate no difference between the two techniques.

In the second study, the highest mean for face-to-face communication was received for clearness $(M=4,27)$ and the least for quickness $(M=$ 3,57), whereas web-based communication received the highest mean for quickness $(M=4,50)$ and the least $(M=3,62)$ for interaction. Again, the findings rightfully acknowledge the time consuming nature of face-to-face communication, while giving credit to web-based communication in that aspect, but the differences are not major (Figure 4) (Table 2).

\section{DISCUSSIONS: A HYBRID SETTING FOR THE DESIGN STUDIO}

The findings provide grounds to assert two major arguments:

1 The students have a strong background in computer use and they are familiar with way finding in virtual environments. With a quick presumption, one would expect them to favor web-based communication in a design environment. However, they hold on to the positive assets of traditional face-to-face communication and do not welcome web-based communication without reservations.

\section{Although students seem to favor face-to-face communication while separately evaluating the communication techniques, when it comes to comparative evaluation, they do not seem to distinguish majorly between the two. In other words, they do not favor one communication alone. Figure 4 shows how close their evalua- tions for both communication techniques are. Therefore it may be asserted that in the design studio students will appreciate an integrated communication framework instead of utilizing one communication technique alone.}

One interesting observation is that although students may get their critiques through virtual platforms whenever they want, without having to come to the design studio, they did not mention this as a positive factor. On the contrary, they indicated that they wanted to know how the others were doing and thus, some groups asked the others how their web-based critiques were. Fiedler (2001) states that invisibility of the instructors and a lack of contact with other students in e-mail communication often makes social interaction difficult, takes away the

\begin{tabular}{|c|r|r|r|r|l|}
\cline { 2 - 6 } \multicolumn{1}{c|}{} & \multicolumn{1}{c|}{ easiness } & interaction & quickness & being stimulative & clearness \\
\hline f-t-f 1 & 4,46 & 4,15 & 4,35 & 3,84 & 3,92 \\
\hline f-t-f 2 & 3,93 & 3,81 & 3,57 & 3,73 & 4,27 \\
\hline w b 1 & 4,53 & 4,00 & 4,20 & 3,69 & 4,38 \\
\hline w b 2 & 4,25 & 3,62 & 4,50 & 4,00 & 4,12 \\
\hline & & & & &
\end{tabular}

Table 2. Comparative assesment of communication types (face-to-face ' second studies

$-108$ 


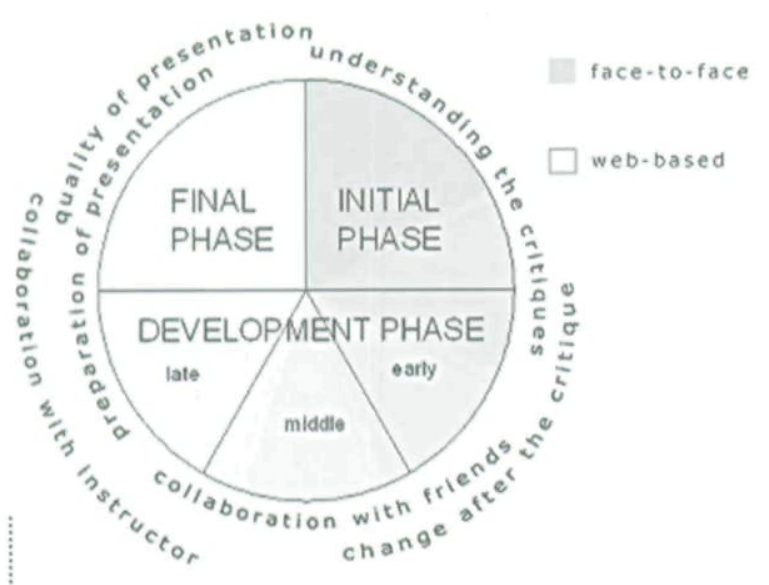

Figure 5. Phases of design process and design communication

personal connection to the class and the instructor, and this results in lack of knowledge about course participants and their projects. It is evident that keeping track of how the others are doing are important for the students and they feel that this is best achieved in the physical classroom. On the other hand, as the design project develops, in the virtual classroom setting, there are opportunities for the students to generate a collective understanding and communication rather than the instructor(s) alone (Hou \& Kang, 2006). Therefore, the hybrid setting for the design studio, in terms of involving physical and virtual encounters, may change as the project evolves.

The project cycle may be divided into three phases: initial, development and final. The initial phase involves generation of ideas, the development phase involves collaboration with friends and the instructor(s), and the final phase focuses on the presentation (Figure 5). Based on the findings, it may be asserted that at the initial phase, the encounters should take place in the physical classroom. As the phases evolve, both physical and the virtual classrooms may be utilized. At the final phase virtual classroom may be used solely.

As the design process requires different means and densities of communication at different stages, the framework may be adapted according to the design phase. For the initial design phase the density of communication should involve face-toface encounters (Figure 6), as the findings suggest understanding the critiques, changes in design and collaboration with the instructor(s) and collaboration with friends are better in physical encounters.

The continuous lines indicate primary communication; while the dashed lines represent secondary communication. The development phase involves both face-to-face and web-based communication (Figure 7). The presence of the student shifts from the physical classroom to the virtual one as the development phase emerges. Simoff and Maher indicate the need for a 'warm-up' period in the schedule of the virtual design studio for those students who have "difficulties in adapting to the reduction of personal physical interaction" (1997: 7). The mixed structuring in the development phase is expected to aid students organize their own pace in shifting to the virtual classroom.

In the final design phase (Figure 8), virtual classroom may be frequented more than the physical one, since the findings suggest that web-based encounters are found to be more satisfactory in quickness, clearness, required preparation load for presentation, and quality of presentation, assets that are more related to the presentation of the finished project.

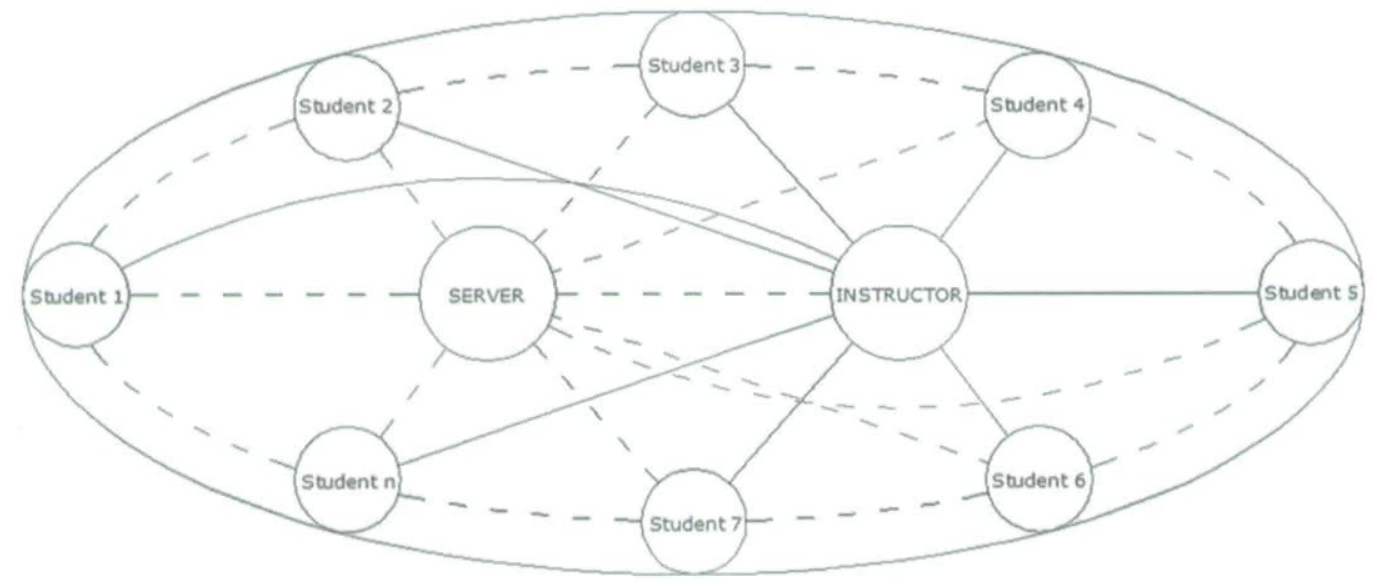

The hybrid framework of communication for the initial design phase 


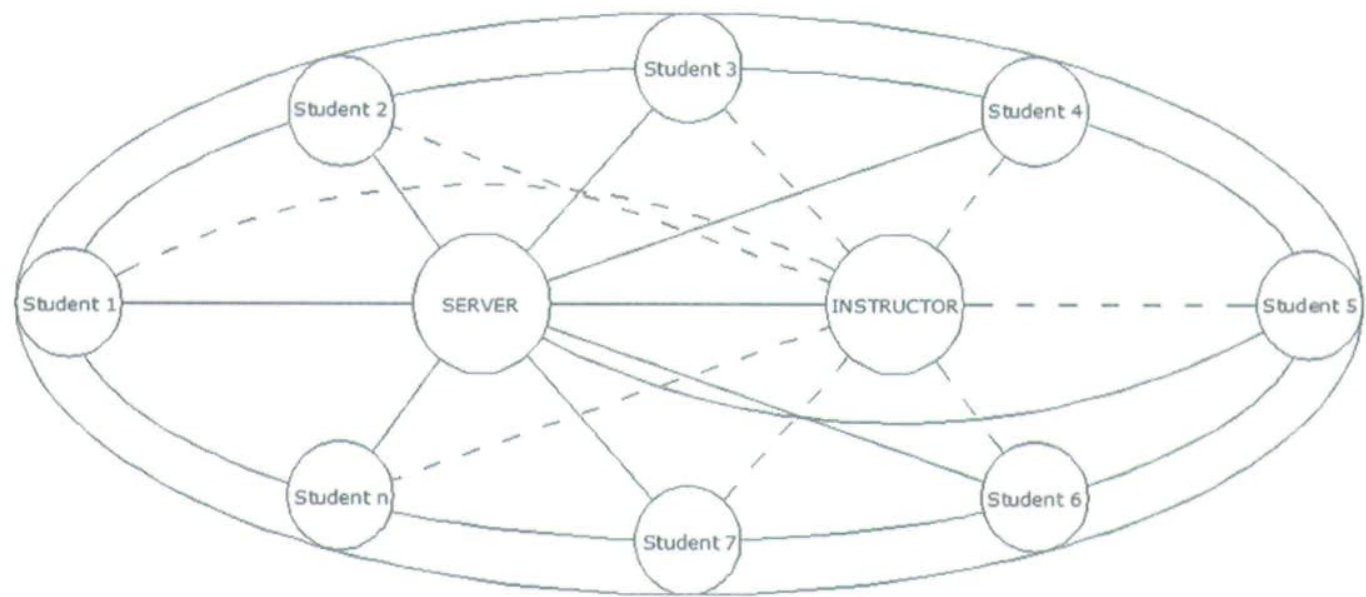

Figure 7. The hybrid framework of communication for the development phase

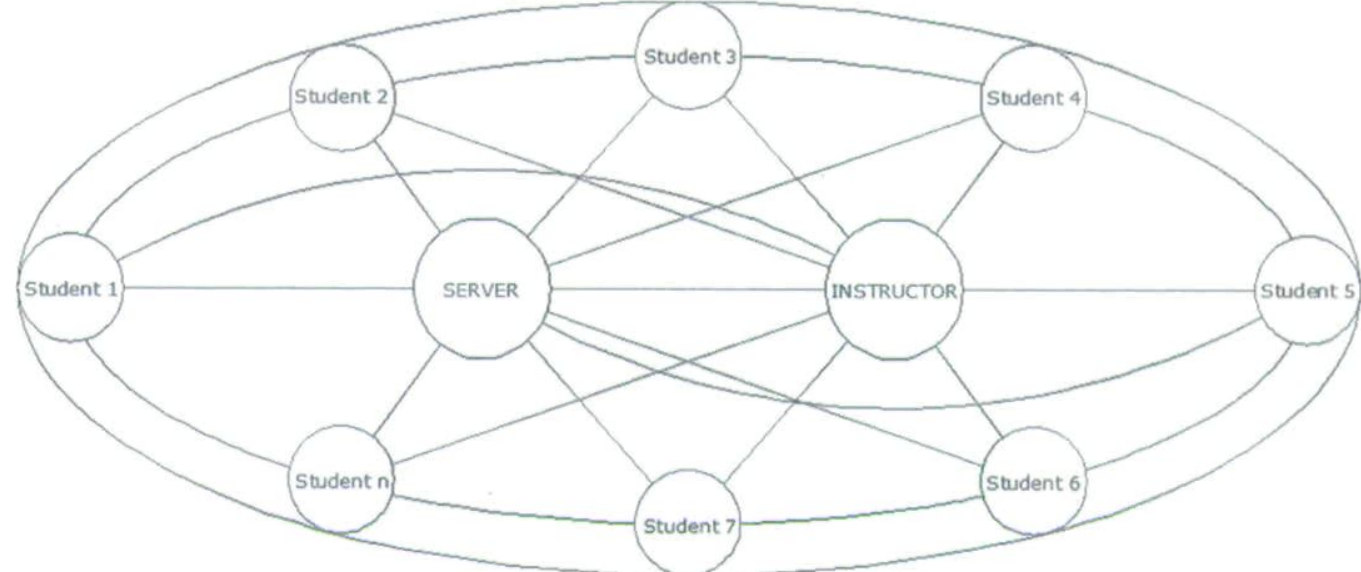

The hybrid framework of communication for the final design phase

\section{CONCLUSION}

This study is an effort towards determining the future setting of the design studio in the emerging power of the virtual classrooms. In order to determine the impact of face-to-face encounters in the physical classroom and web-based encounters in the virtual classroom, a study is held in a hybrid design studio setting. The group of students, who participated in the study, belongs to the current generation that is familiar with using computers. The findings showed that although the students acknowledge many advantages of using computers in design (such as economizing from time and decrease in physical stress in completing various tasks, high capacity and meticulous look of the outputs), they are cautious in their evaluation of the medium. Especially when design communication is involved, students still seem to value the factors inherit in physical encounters, such as facial expression, ability to respond immediately, and possibility of stating themselves verbally. Generating ideas may be faster and more productive while using computers, but students preferred the possibility of talking about the new alternatives quickly during face-to-face encounters and with the presence of classmates.

Considering the discussions that the future design studio will shift from the physical classroom to fully virtual ones, it may be asserted that there will be a transition period where hybrid courses -in hybrid environments- shall take place. Hybrid environments allow for integrated design communication, where face-to-face and virtual encounters are available to the students. Hybrid courses are employed in other fields, but their introduction to the field of design is new. In this study it is proposed that the hybrid setting for the design studio should involve the physical encounters more at the initial phase of design, evolving into a mixed setting of physical and virtual encounters in the design devel- 
opment phase, and having more virtual encounters than the physical ones in the final phase. Such setting needs to be experienced and assessed in further studies in order to establish a beneficial framework for the setting of the design studios in the future.

\section{REFERENCES}

AKKOYUNLU, B. AND SOYLU, M.Y. 2008, A Study of Student's Perceptions in a Blended Learning Environment Based on Different Learning Styles, Educational Technology \& Society, VOI. (1 1), No. (1), PP. 183-193.

AL-QAWASMI, J. 2006, Transformations in Design Education: The Paperless Studio and The Virtual Design Studio, Special Issue on Design Studio Teaching Practices, (ed.) A. M. Salama, Open House International, VOI. (31), No. (3), PP. 95-101.

ANDIA, A. 2002, Internet Studios: Teaching Architectural Design On-Line between the United States and Latin America, Leonardo, Vol. (35), No. (3), PP. 297-302.

BENBUNAN-FICH, R. and HILTZ, S. R. 2003, Mediators of Effectiveness of Online Courses, in IEEE Transactions on Professional Communication, Vol. (46), No. (4), PP. 298-312.

CHENG, N. and KVAN, T. 2000, Design Collaboration Strategies, in SiGraDi 2000:

$4^{\text {th }}$ Iberoamerican Congress of Digital Graphics, Rio de Janeiro.

CLARK, S. and MAHER, M.L. 2005, Learning and Designing in a Virtual Place, J. Duarte, G. DuclaSoares and A. Z. Sampaio (eds) eCAADe23 Digital Design: The Quest for New Paradigms, eCAADe and Insituto Superior Tecnico Lisbon, PP. 303-309.

CLAYTON, M.J. 2000, Design Desk Critiques: Digital or Face-to-Face? $4^{\text {th }}$ Sigradi Conference

Proceedings: Constructing the Digital Space, Sigradi, PP. 41-44.

DENNIS, T., EL-GAYAR, O.F. and ZHOU, Z. 2002, A Conceptual Framework for Hybrid Distance Delivery for Information System Programs, Issues in Information Systems, Vol. (3), PP. 137-143.

EL-GAYAR, O.F. and DENNIS, T. 2005, Effectiveness of Hybrid Learning Environments, Issues in Informations Systems, Vol. (6), No. (1), PP. 176-182.

FIEDLER, S. 2001, The Studio Experience: A Case Study On Self-Direction In Learning Within A Formal Instructional Setting, Diplomarbeit in der Psychologie,
Friedrich-Alexander-Universität Erlangen-Nürnberg.

GARNHAM, C. and KALETA, R. 2002, Introduction to Hybrid Courses, Teaching With Technology Today, Available at: http://www.uwsa.edu/ttt/articles/garnham.ht.

HENSLEY, G. 2005, Creating a Hybrid College Course: Instructional Design Notes and Recommendations for Beginners, Journal of Online Learning and Teaching, Available at: http://jolt.merlot.org/voll_no2_hensley.htm.

HOU, J. and KANG, M.J. 2006, Differences and Dialogic Learning in a Collaborative Virtual Design Studio, Special Issue on Design Studio Teaching Practices, (ed.) A. M. Salama Open House International, Vol. (31), No. (3), PP. 85-94.

HUNDHAUSEN, C.D., NARAYANAN, N.H. and CROSBY, M.E. 2008, Exploring Studio-Based Instructional Models for Computing Education, ACM SIGCSE Bulletin, Vol. 40, №. (1), PP. 392-396.

JOHNSON, J. J. 2002, Reflections on Teaching a Large Enrollment Course Using a Hybrid Format, Teaching With Technology Today, Available at: http://www.uwsa.edu/ttt/articles/ijohnson.htm

KALAY, Y. E. 2004, Virtual Learning Environments, Itcon Special Issue ICT Supported Learning in Architecture and Civil Engineering, Vol. (9), PP. 195207.

KOOHANG, A. and DURANTE, A. 2003, Learners Perceptions toward the Web-based Distance Learning Activities/ Assignments Portion of an Undergraduate Hybrid Inrstructional Model, Journal of Information Technology Education, Vol. (2), PP. 105-113.

LATCHMAN, H. A., SALZMANN, C., THOTTAPILLY, S., and BOUZEKRI, H. 1998, Hybrid Asynchronous and Synchronous Learning Networks in Distance Education, Intemational Conference on Engineering Education, Rio de Janeiro, Brazil

LEVINE, S.L. and WAKE, W.K. 2000, Hybrid Teaching: Design Studios in Virtual Space, presented to the National Conference on Liberal Arts and the Education of Artists SVA, New York, Available at: http://research.the-bac.edu/sva/index.htm.

NGUYEN, T. T. and BODI, J. M. 2007, Online Teaching: The Development of a Hybrid Course in Higher Education, in K. Kumpulainen (ed.) Eductional Technology Opportunities and Challenges, Oulu University Press, Finland, PP. 24 29.

NORMAN, F. 2001, Towards a Paperless Studio, Reinventing the Discourse - How Digital Tools Help Bridge and Transform Research, Education and Practice in Architecture [Proceedings of the $21^{\text {st }}$ 
Annual Conference of the Association for ComputerAided Design in Architecture], Buffalo, PP. 336-343.

OXMAN, R. 2007, Digital Architecture as a Challenge for Design Pedagogy: Theory, Knowledge, Models and Medium, Design Studies, VOI. (29), No. (2), PP. 99-120.

PARKER, D., and ROSSNER-MERRILL, V. 1998 , Socialization of Distance Education: The Web as Enabler, H. Maurer and R. G. Olson (ed.s) WebNet 98: World Conference of the WWW, Internet, and Intranet Proceedings, Association for the Advancement of Computing in Education, Charlottesville, VA.

POLTROCK, S. and ENGELBECK, G. 1999, Requirements for a Virtual Collocation Environment, Information and Software Technology, Vol. (41), PP. 331-339.

REFFAT, R. M. 2002, Designing with Computers in a Paperless Design Computing Studio, A. Eshaq, C. Khong, M. Neo and S. Ahmad (eds) Proceedings of the $7^{\text {th }}$ International Conference on Computer Aided Architectural Design Research in Asia (CAADRIA), Prentice Hall, New York, PP. 347-354.

SIGLE, J., KEY J., CRITCHER, A. and PRINCE, J. 2005, Tools for Hybrid Instruction- Classroom and Distance Instruction in Synchronous and Asynchronous Modes, Information Systems Education Journal, Vol. (3), No. (14), PP. 3-7.

SIMOFF, S. J. and MAHER, M.L. 1997, Design Education via Web-based Environments, in Proceedings of 4th ASCE Congress of Computing in Civil Engineering, ASCE, New York, NY, PP.418-425.

SENYAPILI, B. and KARAKAYA, A.F. 2005, Design Studio Communication: Young Generation Holding on to Old Techniques, in Innovation in Architecture, Engineering and Construction, S. Sariyildiz, et.al. (ed.), Optima Grafische Communicatie, Rotterdam, PP. 375-385.

SENYAPILI, B. and KARAKAYA, A.F. 2006, A Hybrid Framework For Collaboration In Design Curricula, Joint International Conference on Construction Culture, Innovation, and Management Conference Proceedings: Sustainable Development through

Culture and Inn

\section{Authors' Addresses:}

Burcu Senyapili \& Ahmet Fatih Karakaya Faculty of Art, Design and Architecture Bilkent University Ankara, Turkey burcu@bilkent.edu.tr afatih@bilkent.edu.tr 
Copyright of Open House International is the property of Open House International Association and its content may not be copied or emailed to multiple sites or posted to a listserv without the copyright holder's express written permission. However, users may print, download, or email articles for individual use. 